ECCOMAS

Proceedia
COMPDYN 2021

$8^{\text {th }}$ ECCOMAS Thematic Conference on Computational Methods in Structural Dynamics and Earthquake Engineering

M. Papadrakakis, M. Fragiadakis (eds.)

\title{
EXPERIMENTAL AND NUMERICAL ASSESSMENT OF ISOLATION SEISMIC DEVICE FOR RETROFIT OF INDUSTRIAL SHED
}

\author{
L. Mari ${ }^{1}$, V. Quaglini ${ }^{2}$, C. Pettorruso ${ }^{2}$, E. Bruschi ${ }^{2}$ \\ ${ }^{1}$ Moretti S.p.A., Director R\&D \\ via Gandhi 9, 25030 Erbusco (BS), Italy \\ mari@morettispa.it
${ }^{2}$ Politecnico di Milano, Department of Architecture, Built Envinroment and Construction Engineering Piazza Leonardo da Vinci 32, 20133 Milan, Italy
virginio.quaglini@polimi.it
carlo.pettorruso@polimi.it
eleonora.bruschi@polimi.it

\begin{abstract}
Prefabricated industrial sheds featured a high seismic vulnerability during the 2012 Emilia earthquake (Italy). The buildings typically exhibited a rigid collapse mechanism that was a consequence of the lack of connection between columns, beams and roof elements.

The study presents an experimental and numerical assessment of a novel isolation device which has been designed to improve the seismic performance of industrial sheds. The device, which is placed on the top of the column, exploits the movement of a rigid body on a sloped surface to provide horizontal stiffness and control the lateral displacement of the beam.

Biaxial tests are performed to investigate the effect of the vertical load, the velocity of sliding and the number of cycles on the force-displacement response of the device. To cope with the capacity of the testing equipment, the experimental campaign is carried out on a scaled model of the device, and the protocol is designed accounting for similarity requirements. The backbone curve of the tested prototype is eventually derived from the experimental data.

In the second part of the study, a 3D finite element model of the prototype is formulated in Abaqus and used to switch the backbone curve from the scaled model to the full-scale device. A parametric study is conducted to evaluate the influence of the inclination of the sloped surface and the coefficient of friction on the output force of the system.
\end{abstract}

Keywords: Prefabricated sheds; seismic isolation; retrofit; experiments; reinforced concrete. 


\section{INTRODUCTION}

In Italy, the seismic events of L'Aquila 2009, Emilia 2012 and Central Italy 2016 highlighted the vulnerability of the Italian stock on structures and infrastructures that were not designed according to modern seismic regulations.

The Emilia earthquake of May 2012 hit an area with a high density of productive activities, affecting mainly industrial buildings in precast reinforced concrete $(\mathrm{RC})[1,2]$ rather than in steel [3]. This seismic event caused a global economic damage of 13.27 billion of euros and estimates show that the loss of direct and indirect income was between 3 and 3.8 billion [4].

After Emilia earthquakes, the Italian Civil Protection Department prepared a summary (WG 2012) [5] of the main deficiencies of the precast industrial building structural performance. In this regard, it is worth also mentioning the study by Rossi et al. [6] about longspan-beam structure, which proposed a damage characterization to construct empirical fragility functions, cost and loss ratio curves referring to precast RC industrial buildings.

The existing industrial buildings in Italy are mainly characterized by a simple structural layout with columns pin-connected to beams that support the roof, which is an extremely vulnerable configuration under a seismic event. Indeed, the most severe damage, observed also during the event of Emilia 2012, is the loss of support and the consequent collapse of structural and non-structural elements $[1,2]$. This kind of connections usually rely solely on friction and are inadequate to properly transfer the horizontal loads $[7,8,9]$ and accommodate compatible rotations and displacements $[10,11,12,13,14,15]$.

In order to improve the seismic performance of poorly designed or deficient structures, a retrofit intervention needs to be planned and implemented at either local level or global one [3]. Local interventions usually consist of structural strengthening, applying rigid and resistant reinforcement that increase the capacity of deficient elements; such a reinforcement can be made of either steel, or high-strength fibers embedded into a cementitious or a polymeric matrix [16]. Conversely, global interventions are implemented by inserting in the structure particular devices, which either reduce the seismic input, by separating the motion of the superstructure from the motion of the ground (namely seismic isolation systems) or increase the total energy dissipation capacity (namely energy dissipation devices) $[17,18]$ by concentrating on special elements out of the main load bearing structure the dissipation of most of the energy transmitted by the earthquake.

The study presents an experimental and numerical assessment of a novel isolation device which has been designed to improve the seismic performance of industrial sheds. The device, which is placed on the top of the column, exploits the movement of a rigid body on a sloped surface to provide horizontal stiffness, control the lateral displacement of the beam and dissipate with a friction mechanism part of seismic energy. 


\section{DEVICE DESCRIPTION}

The isolation device is composed by two steel elements one concave and the other convex, truncated-pyramidal in shape. The two elements are coupled through the contact, total or partial, of their respective flat surfaces.

This isolation device is designed to be inserted at the junction between the columns and beam of a building and is intended to transmit the vertical load in the node. The horizontal displacement of the beam with respect to the column produced by an earthquake causes the sliding of the convex surface of the first element on the concave surface of the second element. This relative movement generates dissipation of a portion of the seismic energy introduced into the system through the friction generated in correspondence of the sliding contact.

The device is designed to transmit an axial load $\mathrm{N}_{\text {design }}=360 \mathrm{kN}$ and perform a maximum displacement $\mathrm{d}_{\text {design }}=60 \mathrm{~mm}$.

To make the loads developed by the device compatible with the capacity of the test equipment, the characterization was conducted on a prototype scaled by a geometric factor $\mathrm{SL}=0.4$ and fabricated in steel (unit scale factor for modulus of elasticity $\mathrm{SE}=1$ ). Applying the principle of similarity, the scaling factors for all mechanical quantities are determined (Table 1).

\begin{tabular}{lll}
\hline Size & Dimension & Scale factor \\
\hline Length & {$[\mathrm{L}]$} & $S_{L}=0,4$ \\
Elastic Modulus & {$[\mathrm{F}]\left[\mathrm{L}^{-2}\right.$} & $S_{E}=1,0$ \\
Force & {$[\mathrm{F}]$} & $S_{F}=\left(S_{L}\right)^{2}=0,16$ \\
Pressure & {$[\mathrm{F}][\mathrm{L}]^{-2}$} & $S_{p}=1,0$ \\
Displacement & {$[\mathrm{L}]$} & $S_{d}=0,4$ \\
Time & {$[\mathrm{T}]$} & $S_{T}=\left(S_{L}\right)^{1 / 2}=0,6324$ \\
Velocity & {$[\mathrm{L}][\mathrm{T}]^{-1}$} & $S_{V}=\left(S_{L}\right)^{1 / 2}=0,6324$ \\
Frequency & {$[\mathrm{T}]^{-1}$} & $S_{f}=\left(S_{L}\right)^{-1 / 2}=1,5811$ \\
\hline
\end{tabular}

Table 21 Scale factor

This results in the following relationships between the design values of device force and displacement and the values that should be applied in tests to the scaled prototype (Table 2).

\begin{tabular}{lll}
\hline Size & Real scale & Prototype \\
\hline Axial load & $\mathrm{N}_{\text {design }}=360 \mathrm{kN}$ & $\mathrm{N}_{\text {test }}=57,6 \mathrm{kN}$ \\
Displacement & $\mathrm{d}_{\text {design }}=60 \mathrm{~mm}$ & $\mathrm{~d}_{\text {test }}=24 \mathrm{~mm}$ \\
\hline
\end{tabular}

Table 2 Relation between design and test parameters

The scale-down have the dimension shown in Figures 1 and 2. 
$\operatorname{section} A-A$
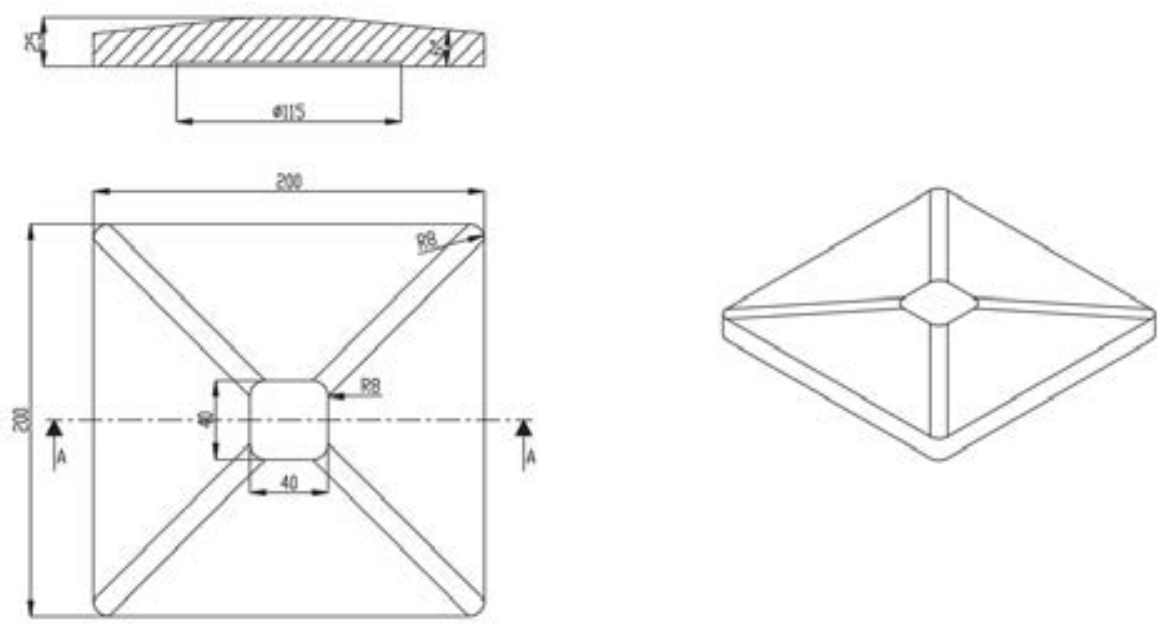

Figure 1 Geometrical characteristics of convex element

xctron $B-B$
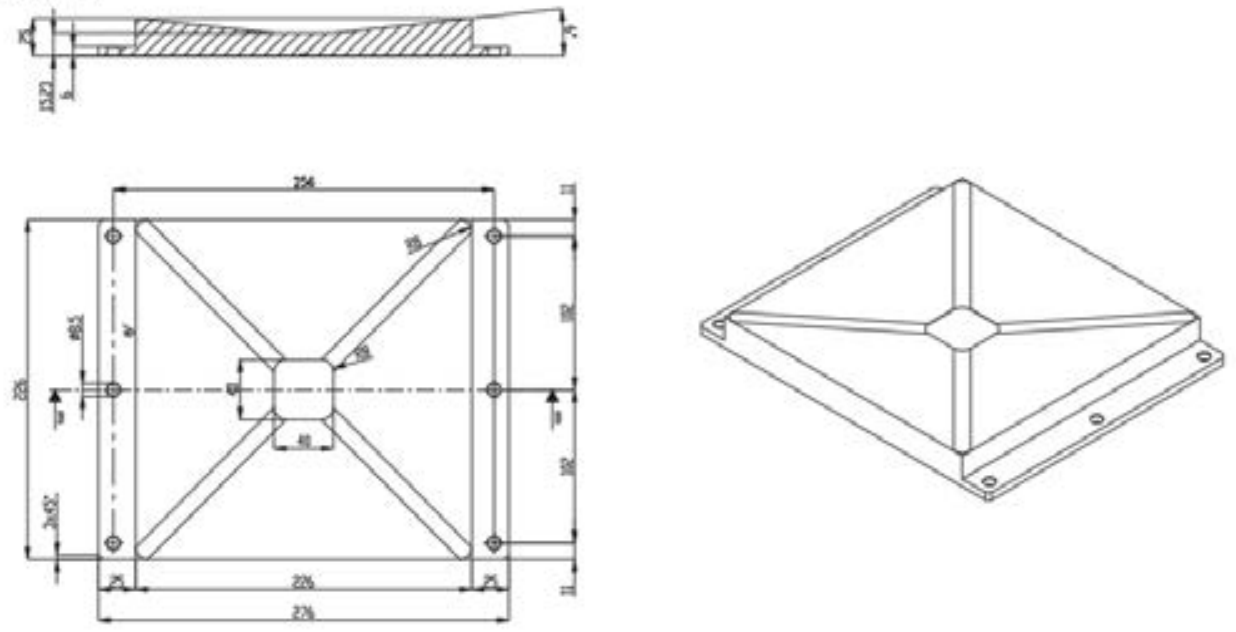

Figure 2 Geometrical characteristics of concave element 


\section{EXPERIMENTAL PROGRAM}

\subsection{Tests setup and instrumentations}

The test is performed on a pair of prototypes of equal size, mounted in an upside-down configuration to minimize the moment arising on the test machine due to the eccentricity of the load applied on the specimen while it is in a translated position.

The concave component is mounted on the moving slide, while the convex component is clamped to a fixed part of the testing machine, to the vertical actuator and the base respectively. The test configuration is shown in Figure 3.
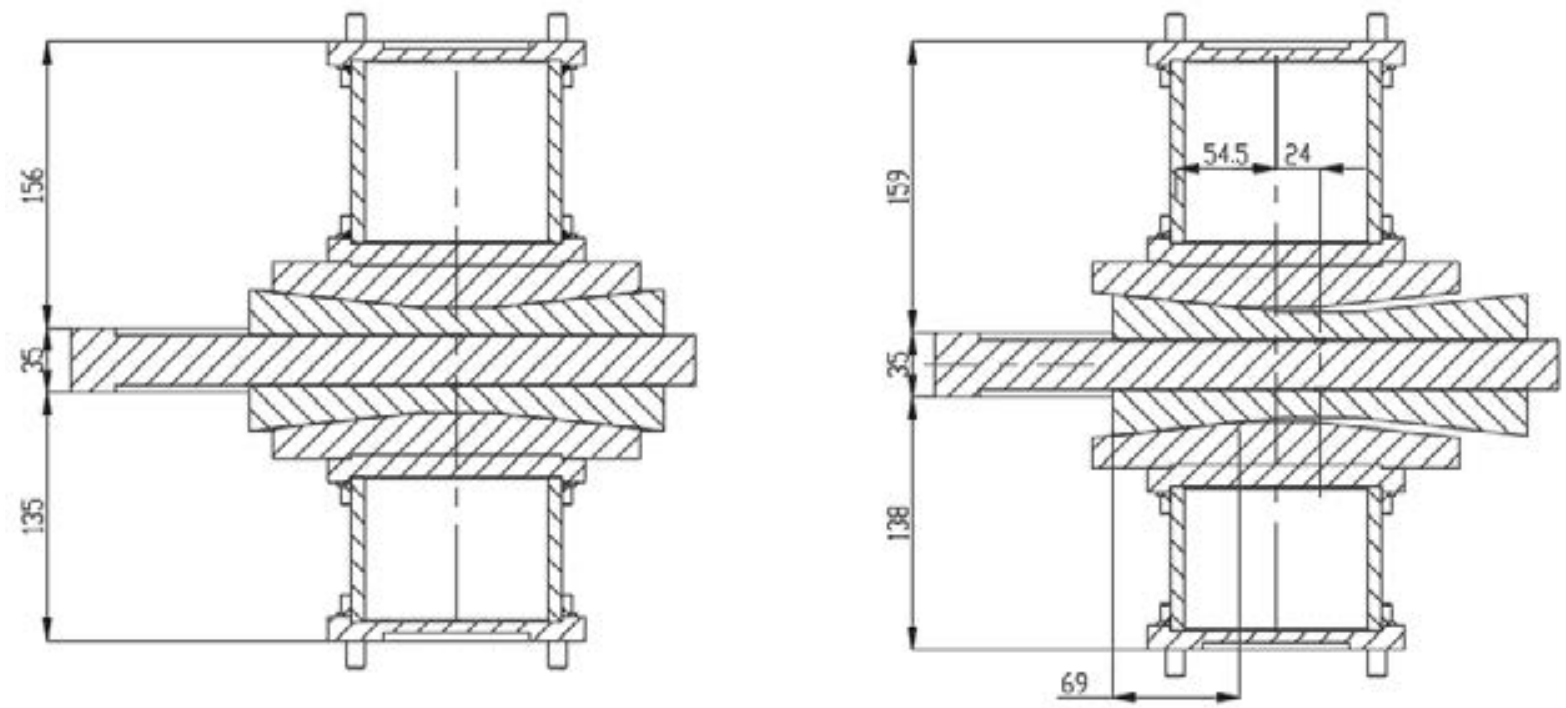

Figure 3 Setup configuration: on the left in centered configuration, on the right in translated position

The tests were conducted on a pair of prototypes with lubrication. Applying the axial load $\mathrm{N}_{\text {test, }}$ kept constant during the test, and simultaneously imposing a horizontal displacement through cycles of amplitude $d_{\text {test }}$ at constant speed $V_{\text {test. }}$. The test protocol, articulated in the execution of static and dynamic tests, reproduced for each combination of prototypes and type of lubrication is specified in Table $3 \mathrm{a}$ for the static and Table $3 \mathrm{~b}$ for dynamic tests.

\begin{tabular}{ccccc}
\hline ID & Axial load & Displacement & Velocity & n. cycles \\
{$[-]$} & $N_{\text {test }}[\mathrm{kN}]$ & $d_{\text {test }}[\mathrm{mm}]$ & $V_{\text {test }}[\mathrm{mm} / \mathrm{s}]$ & {$[-]$} \\
\hline S1 & 14,4 & 24 & 0,672 & 3 \\
S2 & 28,8 & 24 & 0,672 & 3 \\
S3 & 57,6 & 24 & 0,672 & 3 \\
\hline
\end{tabular}

Table 3a Static test 


\begin{tabular}{ccccc}
\hline $\begin{array}{c}\text { ID } \\
{[-]}\end{array}$ & $\begin{array}{c}\text { Axial load } \\
N_{\text {test }}[\mathrm{kN}]\end{array}$ & $\begin{array}{c}\text { Displacement } \\
d_{\text {test }}[\mathrm{mm}]\end{array}$ & $\begin{array}{c}\text { Velocity } \\
V_{\text {test }}[\mathrm{mm} / \mathrm{s}]\end{array}$ & $\begin{array}{c}\text { n. cycles } \\
{[-]}\end{array}$ \\
\hline D2a & 28,8 & 24 & 3,36 & 5 \\
D2b & 28,8 & 24 & 6,72 & 5 \\
D2c & 28,8 & 24 & 16,8 & 5 \\
D2d & 28,8 & 24 & 33,6 & 5 \\
D3a & 57,6 & 24 & 3,36 & 20 \\
\hline
\end{tabular}

Table 3b Dynamic test

Tests were conducted using a biaxial testing system installed at the "Laboratorio Prove Materiali e Strutture per le Costruzioni del Politecnico di Milano". The testing machine consists of a rigid frame with 4 columns and two fixed crossbeams, one lower and one upper, which form a closed ring in which the forces are confined [19].

The main characteristics of the test equipment are:

- Vertical load capacity: $500 \mathrm{kN}$

- Horizontal load capacity: $75 \mathrm{kN}$

- Horizontal displacement capacity: $100 \mathrm{~mm}$

\subsection{Results}

The typical shape of the hysteretic horizontal force (F) - displacement (d) diagram of the prototype seismic device obtained in the cyclic tests is shown in Figure 4. In the forcedisplacement diagrams, the total force acting in the horizontal direction on the pair of prototypes is shown on the y-axis; the reaction force of the individual prototype corresponds to half of the force shown on the diagram.

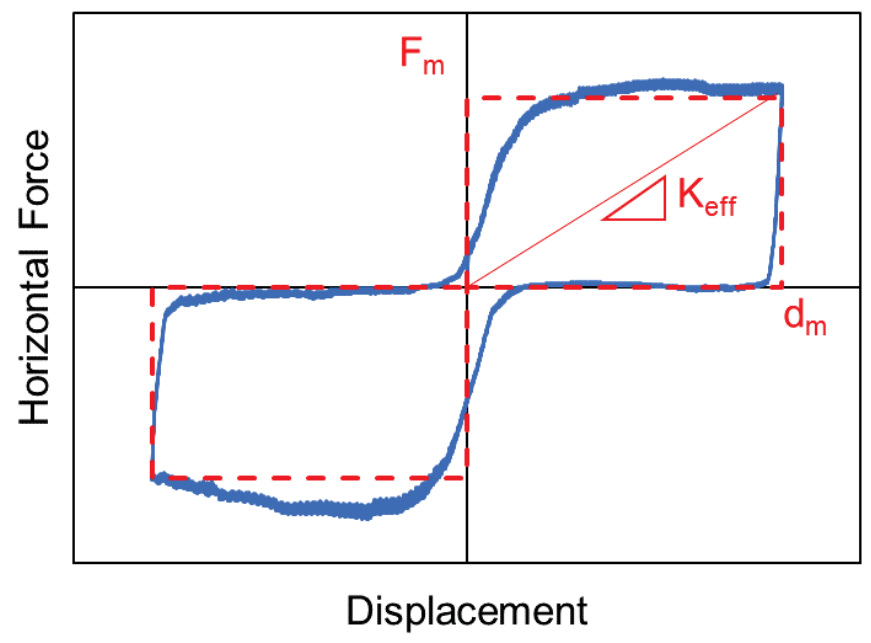

Figure 4 Hysteretic loop

The prototype device has a rigid-plastic constitutive low, characterized by an approximately constant reaction force up to the design displacement. The reaction force is provided by the sum of two contributions, each of which is ideally independent of the magnitude of the displacement: the first is the reaction force to the sliding of the convex element on the inclined plane formed by the surfaces of the concave element, and the second is the friction force generated during sliding. 
In order to identify the characteristic parameters of the prototype, the hysteretic cycle is approximated by two cycles of rectangular shape placed in the first and third quadrant of the plane F - d, and such that the sum of their areas equals the area (A) of the hysteretic cycle itself. Based on energy equivalence considerations, the following parameters are defined:

Energy dissipated in a cycle:

$$
\mathrm{E}_{\text {diss }}=\frac{A}{k_{0}}
$$

Equivalent stiffness:

$$
\mathrm{K}_{\mathrm{eff}}=\frac{E_{\text {diss }}}{2\left(d_{\text {test }}\right)^{2}}
$$

Equivalent dynamic friction coefficient:

$$
\mu_{\mathrm{eff}}=\frac{E_{\text {diss }}}{4 d_{\text {test }} N_{\text {test }}}
$$

where $A[\mathrm{Nm}]$ is the area of the hysteretic cycle, and the factor $k_{0}=2$ takes into account the

\begin{tabular}{|c|c|c|c|c|c|c|}
\hline ID & $\begin{array}{l}\text { Axial } \\
\text { load }\end{array}$ & Velocity & n. cycles & $\begin{array}{c}\text { Energy } \\
\text { dissipated }\end{array}$ & Stiffness & $\begin{array}{l}\text { Friction } \\
\text { coefficient }\end{array}$ \\
\hline$[-]$ & $N_{\text {test }}[\mathrm{kN}]$ & $V_{\text {test }}[\mathrm{mm} / \mathrm{s}]$ & {$[-]$} & $\mathrm{E}_{\mathrm{diss}}[\mathrm{Nm}]$ & $\mathrm{K}_{\mathrm{eff}}[\mathrm{N} / \mathrm{m}]$ & $\mu(-)$ \\
\hline \multirow{3}{*}{ S1 } & \multirow{3}{*}{14,4} & \multirow{3}{*}{0,672} & 1 & 197 & 0,171 & 0,142 \\
\hline & & & 2 & 202 & 0,175 & 0,146 \\
\hline & & & 3 & 207 & 0,18 & 0,150 \\
\hline \multirow{3}{*}{$\mathrm{S} 2$} & \multirow{3}{*}{28,8} & \multirow{3}{*}{0,672} & 1 & 314 & 0,272 & 0,114 \\
\hline & & & 2 & 322 & 0,279 & 0,116 \\
\hline & & & 3 & 331 & 0,287 & 0,120 \\
\hline \multirow{3}{*}{ S3 } & \multirow{3}{*}{57,6} & \multirow{3}{*}{0,672} & 1 & 525 & 0,455 & 0,095 \\
\hline & & & 2 & 539 & 0,468 & 0,097 \\
\hline & & & 3 & 550 & 0,477 & 0,099 \\
\hline
\end{tabular}
fact that the test is conducted simultaneously on two identical prototype devices (Figure 4).

\section{$\underline{\text { Static test }}$}

Table 4 Static test results

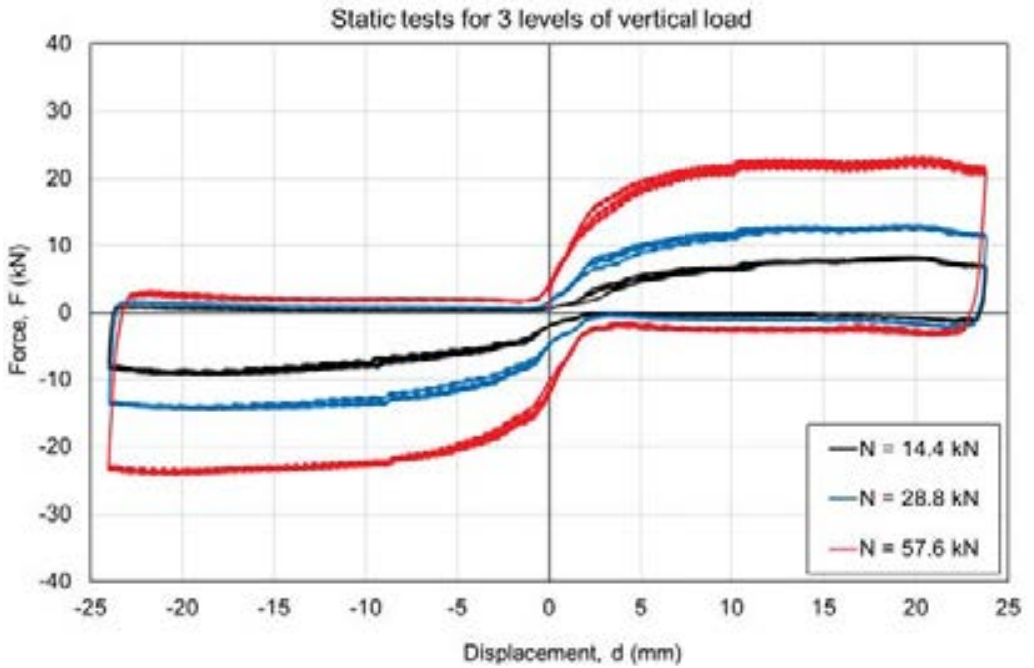

Figure 5 Static test curves 


\section{$\underline{\text { Dynamic test }}$}

\begin{tabular}{|c|c|c|c|c|c|c|}
\hline $\begin{array}{l}\text { ID } \\
{[-]}\end{array}$ & $\begin{array}{c}\text { Axial } \\
\text { load } \\
N_{\text {test }}[\mathrm{kN}]\end{array}$ & $\begin{array}{c}\text { Velocity } \\
V_{\text {test }}[\mathrm{mm} / \mathrm{s}]\end{array}$ & $\begin{array}{c}\text { n. cycles } \\
{[-]}\end{array}$ & $\begin{array}{c}\text { Energy } \\
\text { dissipated } \\
\text { E }_{\text {diss }}[\mathrm{Nm}]\end{array}$ & $\begin{array}{c}\text { Stiffness } \\
\mathrm{K}_{\text {eff }}[\mathrm{N} / \mathrm{m}]\end{array}$ & $\begin{array}{c}\text { Friction } \\
\text { coefficient } \\
\mu(-)\end{array}$ \\
\hline \multirow{5}{*}{$\mathrm{D} 2 \mathrm{a}$} & \multirow{5}{*}{28,8} & \multirow{5}{*}{3,36} & 1 & 326 & 0,282 & 0,118 \\
\hline & & & 2 & 335 & 0,29 & 0,121 \\
\hline & & & 3 & 338 & 0,293 & 0,122 \\
\hline & & & 4 & 339 & 0,293 & 0,123 \\
\hline & & & 5 & 340 & 0,295 & 0,123 \\
\hline \multirow{5}{*}{$\mathrm{D} 2 \mathrm{~b}$} & \multirow{5}{*}{28,8} & \multirow{5}{*}{6,72} & 1 & 324 & 0,28 & 0,117 \\
\hline & & & 2 & 327 & 0,283 & 0,119 \\
\hline & & & 3 & 330 & 0,285 & 0,119 \\
\hline & & & 4 & 330 & 0,285 & 0,12 \\
\hline & & & 5 & 332 & 0,287 & 0,12 \\
\hline \multirow{5}{*}{$\mathrm{D} 2 \mathrm{c}$} & \multirow{5}{*}{28,8} & \multirow{5}{*}{16,8} & 1 & 335 & 0,289 & 0,121 \\
\hline & & & 2 & 330 & 0,285 & 0,119 \\
\hline & & & 3 & 332 & 0,286 & 0,12 \\
\hline & & & 4 & 333 & 0,287 & 0,12 \\
\hline & & & 5 & 334 & 0,288 & 0,121 \\
\hline \multirow{5}{*}{ D2d } & \multirow{5}{*}{28,8} & \multirow{5}{*}{33,6} & 1 & 375 & 0,324 & 0,134 \\
\hline & & & 2 & 353 & 0,304 & 0,126 \\
\hline & & & 3 & 352 & 0,304 & 0,126 \\
\hline & & & 4 & 353 & 0,304 & 0,126 \\
\hline & & & 5 & 354 & 0,305 & 0,126 \\
\hline
\end{tabular}

Table 5 Dynamic test D2 results

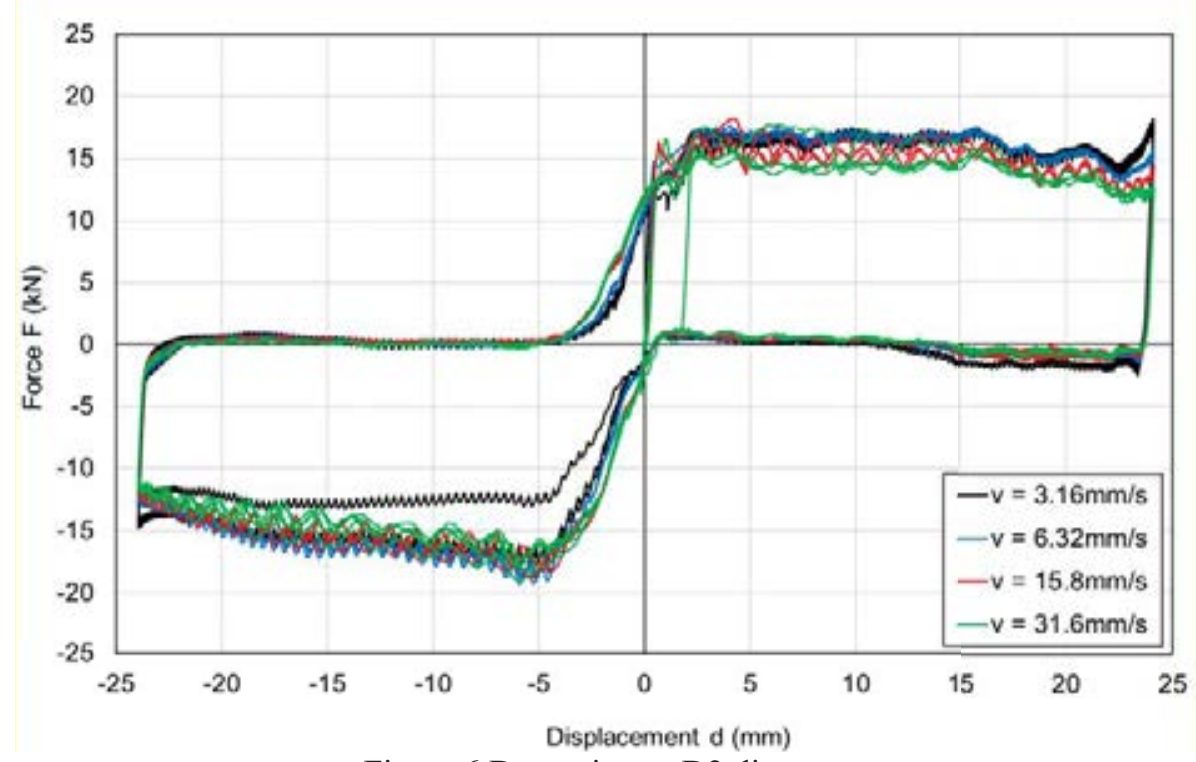

Figure 6 Dynamic test D2 diagram 


\begin{tabular}{|c|c|c|c|c|c|c|}
\hline $\begin{array}{l}\text { ID } \\
{[-]}\end{array}$ & $\begin{array}{c}\text { Axial } \\
\text { load } \\
N_{\text {test }}[\mathrm{kN}]\end{array}$ & $\begin{array}{c}\text { Velocity } \\
V_{\text {test }}[\mathrm{mm} / \mathrm{s}]\end{array}$ & $\begin{array}{c}\text { n. cycles } \\
{[-]}\end{array}$ & $\begin{array}{c}\text { Energy } \\
\text { dissipated } \\
\mathrm{E}_{\text {diss }}[\mathrm{Nm}]\end{array}$ & $\begin{array}{c}\text { Stiffness } \\
\mathrm{K}_{\mathrm{eff}}[\mathrm{N} / \mathrm{m}]\end{array}$ & $\begin{array}{c}\text { Friction } \\
\text { coefficient } \\
\mu(-)\end{array}$ \\
\hline \multirow{20}{*}{ D3a } & \multirow{20}{*}{57,6} & \multirow{20}{*}{3,6} & 1 & 530 & 0,459 & 0,096 \\
\hline & & & 2 & 537 & 0,465 & 0,097 \\
\hline & & & 3 & 539 & 0,467 & 0,097 \\
\hline & & & 4 & 545 & 0,471 & 0,098 \\
\hline & & & 5 & 547 & 0,473 & 0,099 \\
\hline & & & 6 & 551 & 0,477 & 0,1 \\
\hline & & & 7 & 551 & 0,477 & 0,1 \\
\hline & & & 8 & 558 & 0,483 & 0,101 \\
\hline & & & 9 & 559 & 0,484 & 0,101 \\
\hline & & & 10 & 560 & 0,485 & 0,101 \\
\hline & & & 11 & 560 & 0,485 & 0,101 \\
\hline & & & 12 & 562 & 0,487 & 0,102 \\
\hline & & & 13 & 564 & 0,489 & 0,102 \\
\hline & & & 14 & 568 & 0,492 & 0,103 \\
\hline & & & 15 & 568 & 0,492 & 0,103 \\
\hline & & & 16 & 570 & 0,493 & 0,103 \\
\hline & & & 17 & 571 & 0,494 & 0,103 \\
\hline & & & 18 & 571 & 0,494 & 0,103 \\
\hline & & & 19 & 573 & 0,496 & 0,104 \\
\hline & & & 20 & 573 & 0,496 & 0,104 \\
\hline
\end{tabular}

Table 6 Dynamic test D3 result

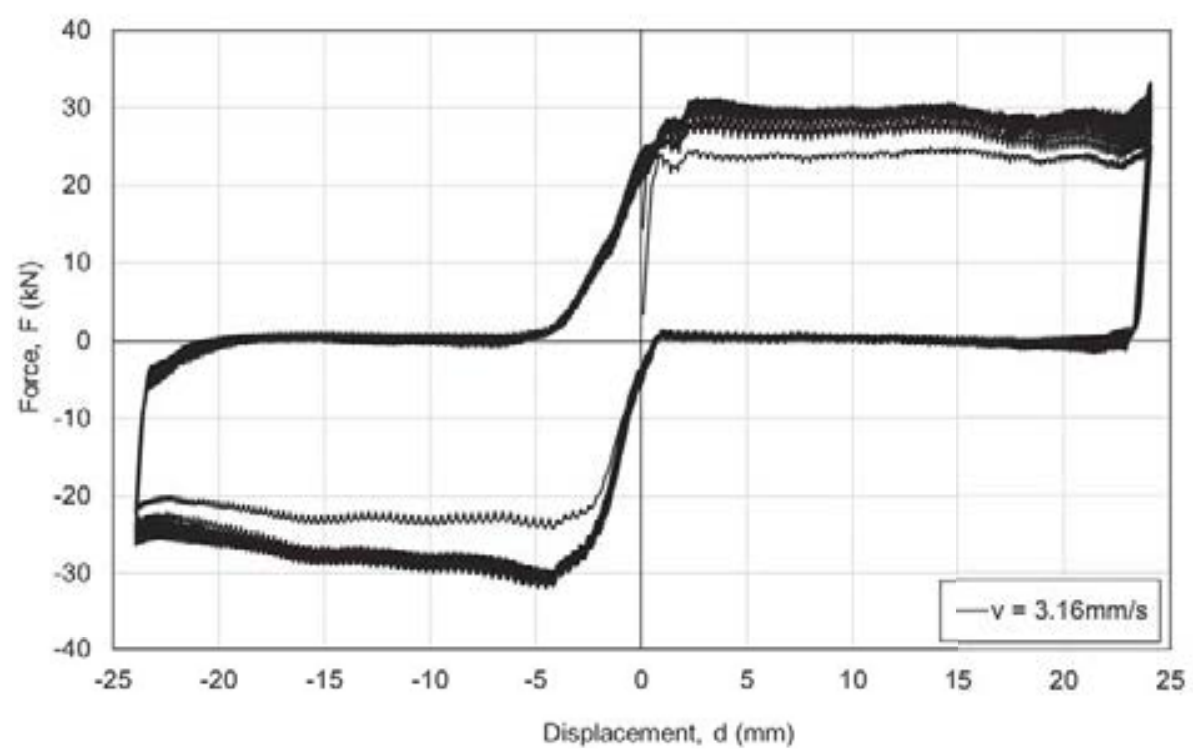

Figure 7 Dynamic test D3 diagram 


\section{NUMERICAL MODEL}

\subsection{Numerical description}

Numerical model of the seismic isolation device described above was developed using the Abaqus CAE finite element calculation program [20].

The geometry of the numerical model of the prototype represents the one described previously that was subjected to experimental characterization tests at the Politecnico di Milano.

The numerical model takes into account only one device, and so there is only two elements, one convex and one concave. To simulate the behavior of the prototype it is developed an implicit dynamic analysis with full Newton solution technique.

The FEM model, like the prototype, is subject to a biaxial load. The boundary conditions that characterize the convex element are the distributed pressure of $11 \mathrm{MPa}$, whose resultant is $57,6 \mathrm{kN}$, applied on the external face, and the harmonic displacement with amplitude $24 \mathrm{~mm}$. The concave element is fixed.

The numerical model was mashed with elements C3D8 (three-dimensional hexahedral element with 8 nodes) with maximum dimension equal to $8 \mathrm{~mm}$. A total of \#1016 elements were used for the convex element and \#2034 elements for the concave element (Figure 8). The contact between the surfaces in creeping contact was modeled through the surface-tosurface contact command, defining the convex element as the master element, and formulating a hard contact constitutive behavior in the direction perpendicular to the contact surface, and a penalty constitutive behavior tangentially the contact surface [21]. The elements have elastic properties, Young modulus equal to $\mathrm{E}=210^{\prime} 000 \mathrm{MPa}$ and Poisson's coefficient $v=$ 0.30 , corresponding to the characteristics of steel. The friction coefficient between the surfaces of the concave and convex element, based on experimental tests conducted on a device with lubricated surfaces, is assumed to be $\mu=0.10$.

In the numerical modeling, in the absence of precise indications, it was assumed that in the initial configuration with perfectly centered concave and convex elements the two elements are in contact through the two flat faces.

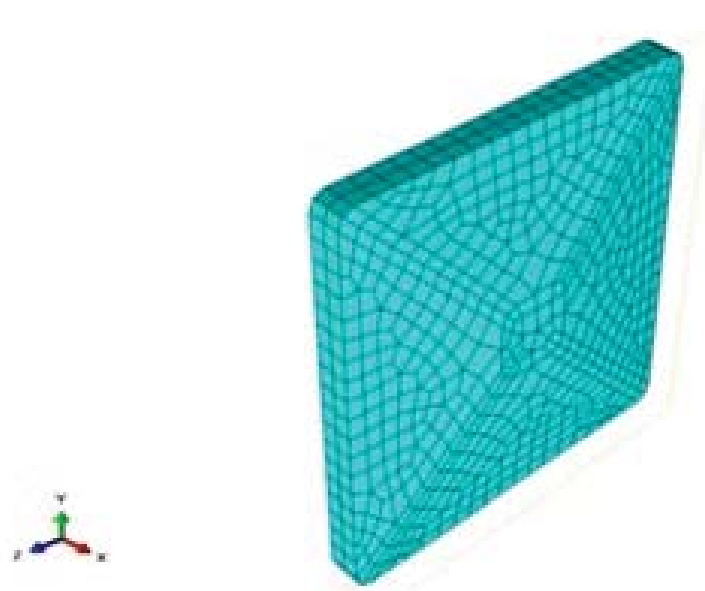

(a)

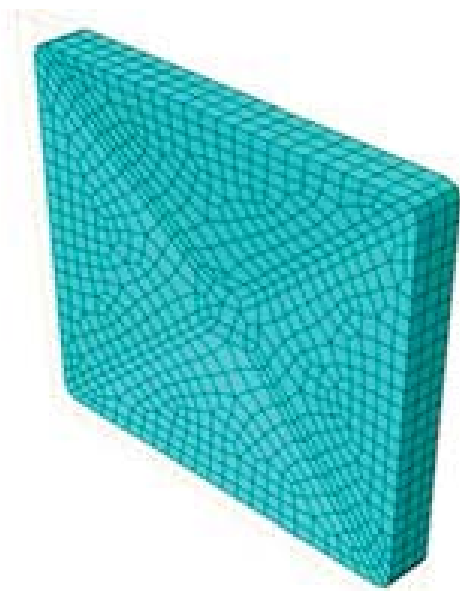

(b)

Figure 8 FEM model of the seismic energy dissipation device:(a) convex element; (b) concave element 


\subsection{Numerical result}

The results of the numerical analyses are shown below for different motion trajectories of the convex component with respect to the concave component defined by angle $\theta$ (Figure 9). The seismic dissipation device has four axes of symmetry, defined by the angles $\theta=0^{\circ}, \theta=$ $+90^{\circ}, \theta=+45^{\circ}$, and $\theta=-45^{\circ}$, the motions along two unidirectional trajectories were analyzed, directed according to the directions corresponding to the angles $\theta=0^{\circ}$ and $\theta=45^{\circ}$, since the other two have the same characteristics as the two considered.

The results are expressed in the form of:

- force-displacement curves:

- reaction force vs. displacement

- reaction moment vs. displacement

- contact pressure distribution

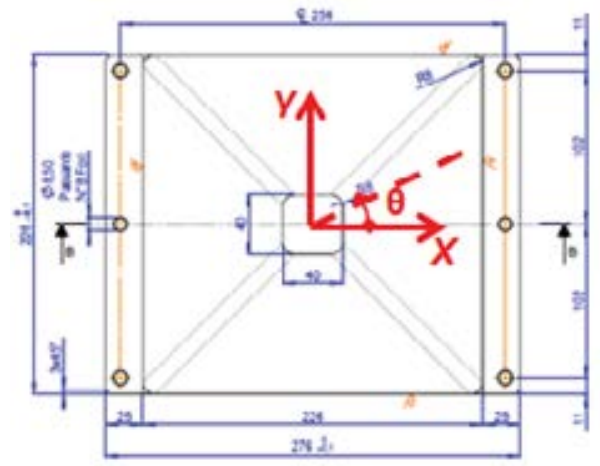

Figure 9 Definition of the reference system for the displacements

Figures 10 and 11 illustrate the force-displacement diagrams related to the analyses conducted imposing a unidirectional movement along the symmetry directions $\theta=0^{\circ}$ and $\theta=+45^{\circ}$.

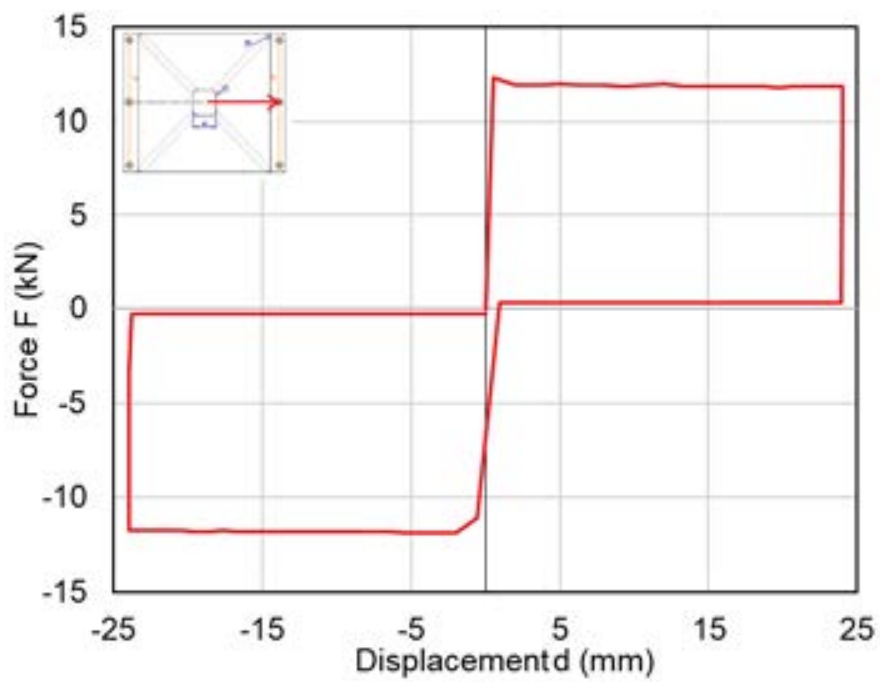

Figure 10 Force-displacement curve for unidirectional trajectory in direction $\theta=0^{\circ}$ 


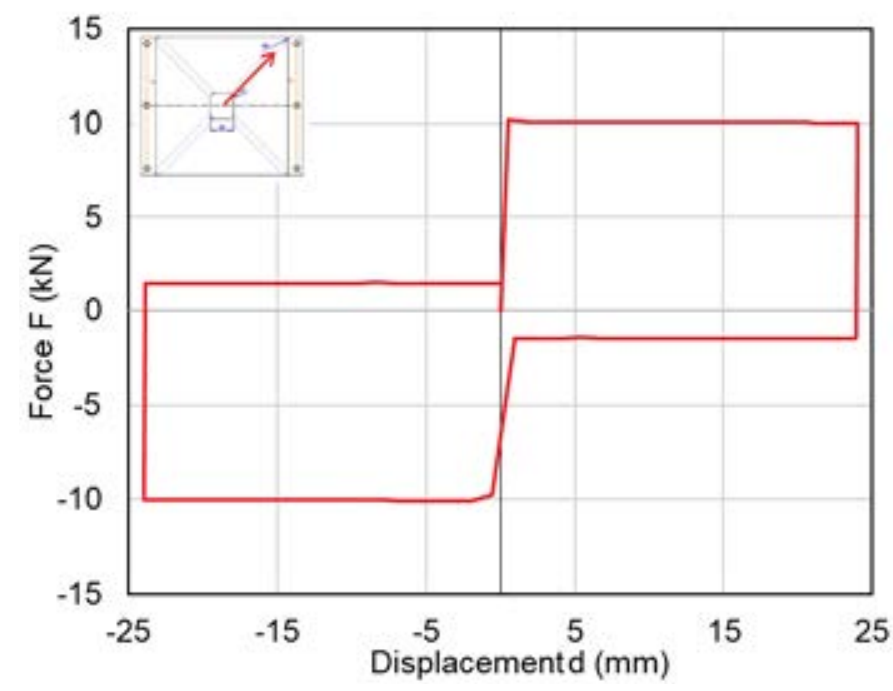

Figure 11 Force-displacement curve for unidirectional trajectory in direction $\theta=45^{\circ}$

The characteristic curve of the device moving according to a direction of symmetry presents the classical flag-shaped that characterizes a constant reaction force independent of the imposed displacement, but dependent on the direction of displacement. This behavior is consistent with the theoretical behavior corresponding to the movement of a solid on an inclined plane with friction, which provides a reaction force of the type

$$
\mathrm{F}=\mathrm{N}[\sin \alpha \cdot \operatorname{sign}(\mathrm{d})+\mu \cos \alpha \cdot \operatorname{sign}(\mathrm{V})]
$$

where $\mathrm{F}$ is the horizontal reaction, $\mathrm{d}$ is the imposed displacement, $\mathrm{N}$ is the vertical compressive load, $\alpha$ is the tilt angle of the sliding surface, $\mu$ is the coefficient of friction, $V$ is the sliding velocity, and $\operatorname{sign}(\cdot)$ is the sign function. The first term on the right in Eq. (4) represents just the reaction force produced by motion on an inclined surface and the second term on the right the friction force:

- the effective angle of inclination $\alpha$ of the device surface along the direction in which the trajectory develops is not constant but varies as the direction of motion defined by the angle $\theta$ varies according to the relation

$$
\alpha(\theta)=\max \left\{\arctan \left(\mathrm{h} / \mathrm{L} 0^{\circ} \cdot \cos \theta\right) ; \arctan \left(\mathrm{h} / \mathrm{L} 0^{\circ} \cdot \operatorname{sen} \theta\right)\right\}
$$

where $\mathrm{h}$ and $\mathrm{L}_{0}$ are defined in figure 12 .

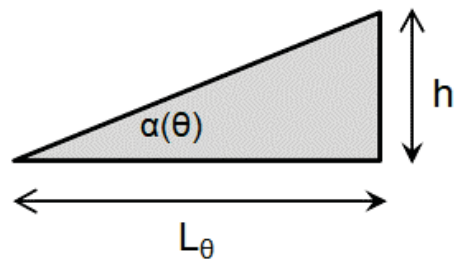

Figure 12 Descriptive geometric parameters of surface inclination along a generic direction $\theta$

The equation (4) expresses the reaction force developed by the seismic dissipation device in the direction of motion, parallel to the trajectory of the convex component with respect to the concave component. On the other hand, the reaction force developed in the direction perpendicular to the trajectory is zero (Figure 13), and this is justified by the symmetry of the contact surfaces with respect to the direction of motion. 


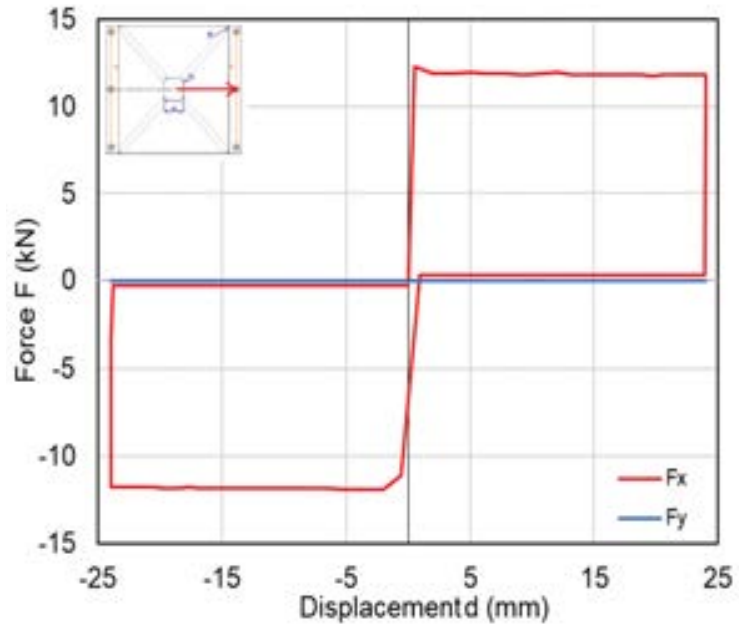

(a)

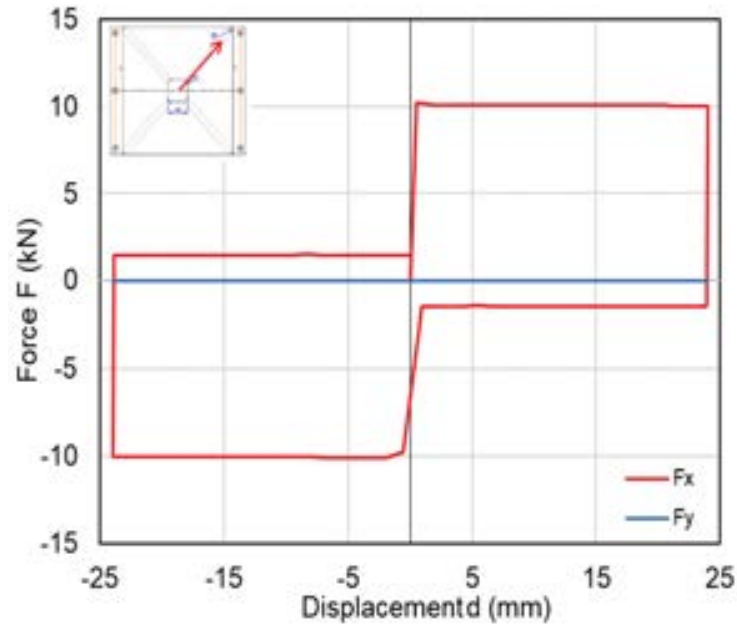

(b)

Figure 13 Reaction force parallel and perpendicular to the direction of motion: (a) $\theta=0^{\circ}$; (b) $\theta=45^{\circ}$

The reaction bending moment evaluated at the top of the column is shown in Figures 14. In agreement with the results presented in Figure 13, the moment acts only in the plane parallel to the direction of displacement, while the moment $\mathrm{M}_{\mathrm{y}}$ acting in the perpendicular plane is zero. The moment has two contributions, one due to the horizontal reaction force $\mathrm{F}$ produced by the movement along the inclined plane, and the other due to the eccentricity of the vertical force $\mathrm{N}$ due to the displacement of the convex element.

The moment presents non-negligible values (equal to about $50 \%$ of the moment at maximum displacement) already for very small movements starting from the initial centered configuration, given by the product of the force $\mathrm{F}$ for the distance of its center of application from the base of the concave element (equal to the thickness of the plate), and grows further with the horizontal displacement $d$ due to the vertical displacement of the center of application and especially by the eccentricity of the vertical force $\mathrm{N}$ that grows linearly with the displacement $\mathrm{d}$.

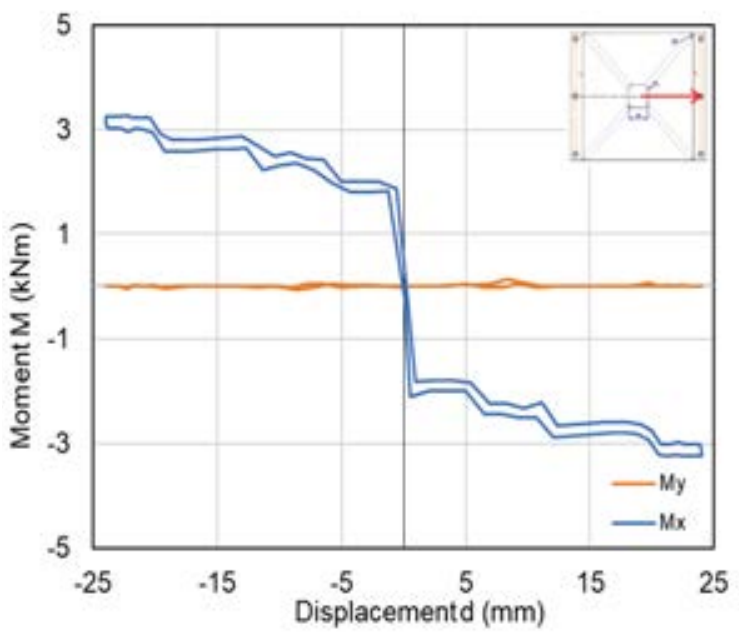

(a)

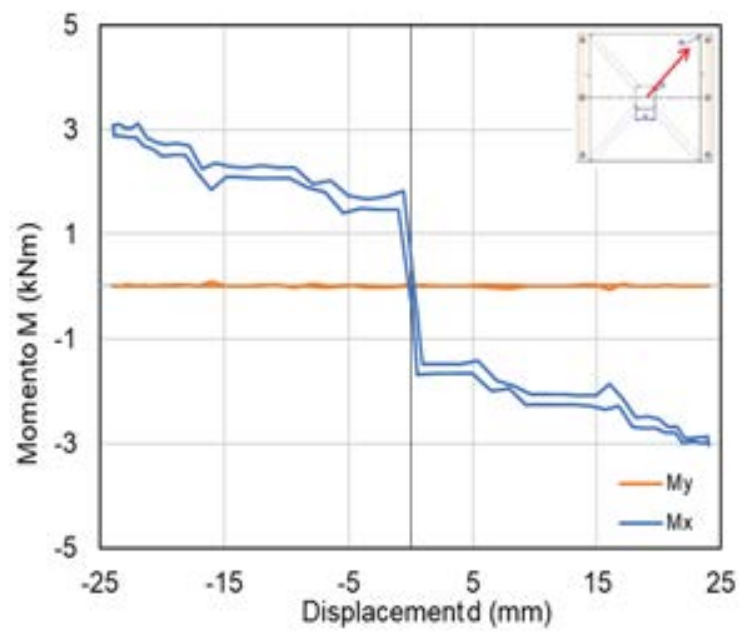

(b)

Figure 14 Bending moment at the top of the column: (a) $\theta=0^{\circ}$; (b) $\theta=45^{\circ}$ 
Figure 15 shows the distribution of contact pressures on the surface of the concave element for different values of displacement $d$, relative to the analysis with trajectory in the direction $\theta=0^{\circ}$. As can be seen, the contact initially occurs at the horizontal plane at the bottom of the concave surface, but as the convex component begins to move, the contact is transferred to the inclined surface along which the motion develops. However, the contact remains localized over a limited area of the surface, corresponding to the area over which the tapered end of the convex member crawls, resulting in high contact pressures that, although below the yield strength of the steel, can potentially accelerate surface wear.
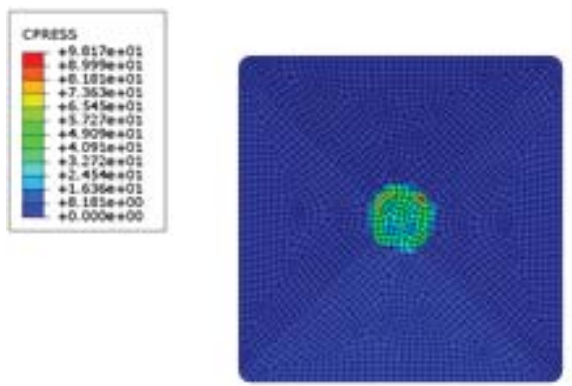

$\mathrm{d}=0,0 \mathrm{~mm}$
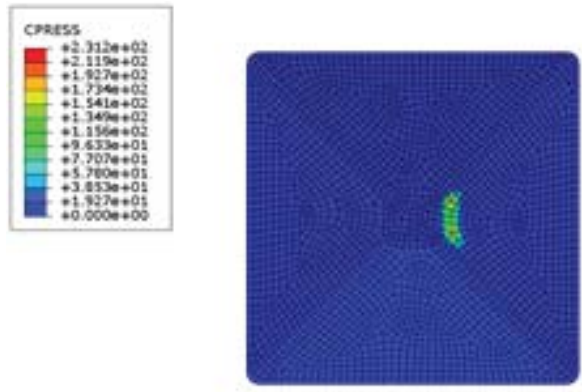

$\mathrm{d}=0,052 \mathrm{~mm}$
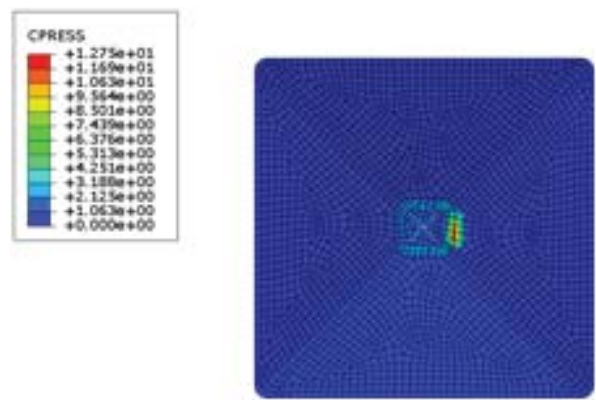

$\mathrm{d}=0,0048 \mathrm{~mm}$
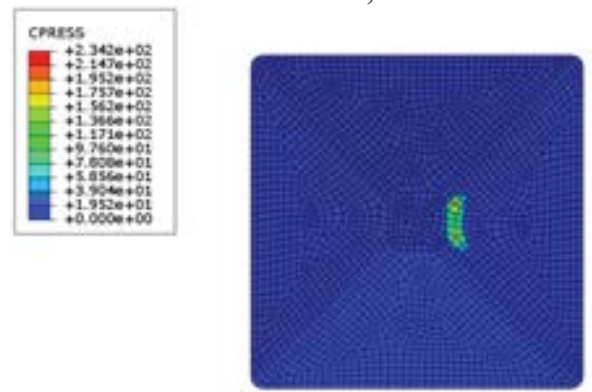

$\mathrm{d}=4,8 \mathrm{~mm}$

Figure 15 Contact pressures on the surface of the concave element for different values of displacement $d$ 


\section{DISCUSSION AND CONCLUSIONS}

The force-displacement curves obtained from the numerical analyses carried out on the prototype and the corresponding experimental curves obtained in the experimental tests are compared in Figure 16.

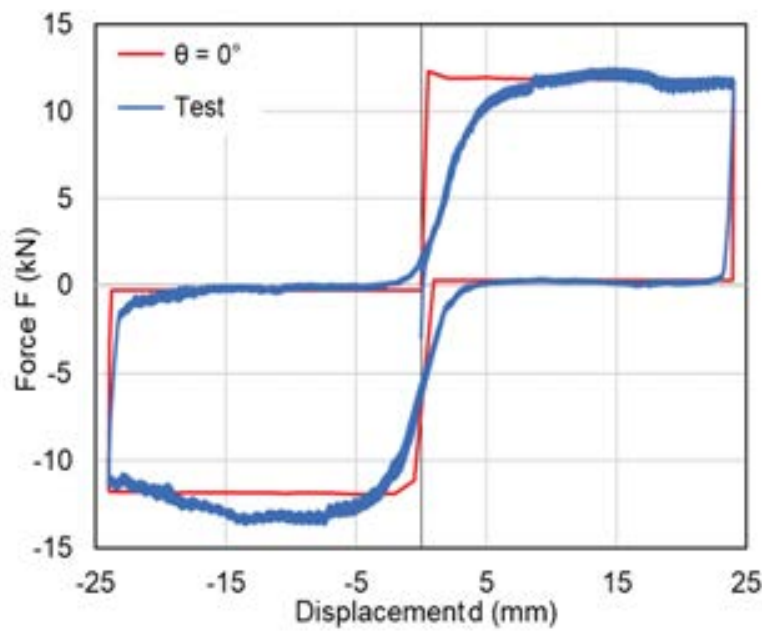

(a)

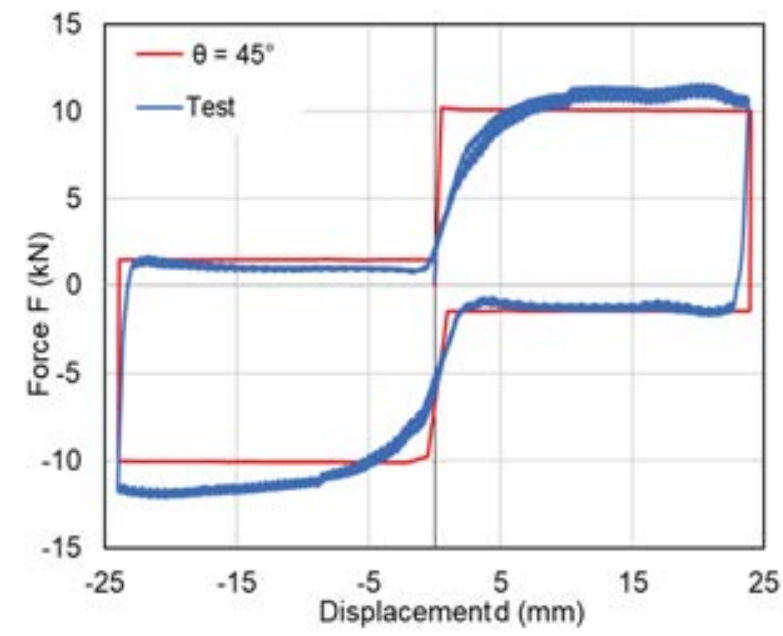

(b)

Figure 16 Experimental and numerical force-displacement curve: (a) $\theta=0^{\circ}$; (b) $\theta=45^{\circ}$

An acceptable correspondence between the experimental curves and the results of the numerical analyses is apparent. The biggest deviations are near the origin of the displacements and are attributed to the effective geometry of contact between the surfaces in the centered configuration of the device. Since the construction drawings provided by the customer and used for the formulation of the numerical model do not give indications on the construction tolerances, it was not possible to define a priori the characteristics of the initial contact to be reproduced in the analysis.

The horizontal reaction force is kept constant for displacements increasing in modulus and is only weakly influenced by the direction of the trajectory $\left(\theta=0^{\circ}\right.$ vs. $\left.\theta=45^{\circ}\right)$, moreover this response is perfectly consistent with that predicted by a simplified analytical model that takes into account the reaction generated by the movement on an inclined plane and the reaction due to friction between surfaces.

Starting from the compared curves, the numerical model results validated. This allows to proceed to the development of the same starting first from a numerical study, to highlight possible criticalities of this device.

Among the developments will be interesting the study of one-dimensional trajectories along non-symmetrical axes and possible two-dimensional trajectories. In addition, as shown in the results of numerical analysis, a problem to be solved is the presence of the moment at the top of the column; it is possible through the development of this model to evaluate the possibility of introducing a hinge under the concave element in order to avoid eccentricity of the load.

Finally, it will be possible to model an industrial shed with the seismic dissipation device in order to evaluate the actual benefits induced by the presence of the devices. 


\section{REFERENCES}

[1] A. Belleri, M. Torquati, P. Riva, R. Nascimbene, Vulnerability assessment and retrofit solutions of precast industrial structures, Earthquakes and Structures, Vol. 8 No. 3 (2015) 801-820.

[2] M. Bosio, A. Belleri, P. Riva, A. Marini, Displacement-Based Simplified Seismic Loss Assessment of Italian Precast Buildings, Journal of Earthquake Engineering 2020, Vol. 24 , No. S1, 60-81.

[3] A. Formisano, G. Di Lorenzo, R. Landolfo, Seismic retrofitting of industrial steel buildings hit by the 2012 Emilia-Romagna earthquake: a case study, Conference Proceedings - October 2018.

[4] E. Artioli, R. Battaglia, A. Tralli, Effects of 2012 Emilia earthquake on industrial buildings of early '900 on the Po river line, Engineering Structures, 56 (2013) 1220-1233.

[5] "Linee di indirizzo per interventi locali e globali su edifici industriali mono piano non progettati con criteri anti-sismici", Avallabile from: http://www.reluis.it/Linee_di_indirizzo_GDL_Capannoni.pdf

[6] L. Rossi, M. Stuppazzini, D. Parisi, B. Holtschoppen, G. Ruggieri, C. Butenweg, Empirical Fragility Functions and loss curves for Italian business facilities based on the 2012 Emilia-Romagna earthquake official database, Bulletin of Earthquake Engineering 2020, 18:1693-1721.

[7] G. Magliulo, G. Fabbrocino, G. Manfredi, "Seismic assessment of existing precast industrial buildings using static and dynamic nonlinear analyses", Earthquakes Structures 2008, 30(9), 2580-2588

[8] L. Liberatore, L. Sorrentino, D. Liberatore, LD. Decanini, "Failure of industrial structures induced by the Emilia (Italy) 2012 earthquakes", Engineering Failure Analysis 2013, 34, 629-647.

[9] A. Belleri, B. Moaveni, J.I. Restrepo, (2014), "Damage assessment through structural identification of a three-story large-scale precast concrete structure", Earthquake Engineering Structure Dynamic., 43(1), 61-76.

[10] A. Belleri, E. Brunesi, R. Nascimbene, M. Pagani, and P. Riva, Seismic performance of precast industrial facilities following major earthquakes in the Italian territory. Journal of Performance of Constructed Facilitiesdoi $2014: 10.1061$

[11] A. Belleri, M. Torquati, P. Riva, and R. Nascimbene. Vulnerability assessment and retrofit solutions of precast industrial structures. Earthquake and Structures 2015, 8 (3): 801-20.

[12] E. Brunesi, R. Nascimbene, D. Bolognini, D. Bellotti. Experimental investigation of the cyclic response of reinforced precast concrete framed structures. PCI Journal 2015 (2): $57-79$.

[13] C. Casotto, V. Silva, H. Crowley, R. Nascimbene, R. Pinho. Seismic fragility of Italian RC precast industrial structures. Engineering Structures 2015 94: 122-36.

[14] Colombo, A., P. Negro, G. Toniolo, and M. Lamperti.2016. Design guidelines for precast structures with cladding panels. JRC Technical report 
[15] C. Demartino, I. Vanzi, G. Monti, C. Sulpizio. Precast industrial buildings in Southern Europe: Loss of support at frictional beam-to-column connections under seismic actions. Bulletin of Earthquake Engineering 2016 (1): 259-94.

[16] F. Mazza, M. Mazza, Seismic retrofitting of gravity- loads designed r.c. framed buildings combining CFRP and hysteretic damped braces, Bulletin of Earthquake Engineering 2019, 17:3423-3445.

[17] D. A. Bournas, P. Negro,F. Taucer, Performance of industrial buildings during the Emilia earthquakes in Northern Italy and recommendations for their strengthening, Bulletin of Earthquake Engineering 2014, vol. 12, 2383-2404.

[18] P. Martinelli, M. G. Mulas, An innovative passive control technique for industrial precast frames, Earthquake Structures 2010: 32 1123-1132.

[19] V. Quaglini, P. Dubini, C. Poggi, Experimental assessment of sliding material for seismic isolation system, Bulletin of Earthquake Engineering, 2012 10:717-740

[20] Abaqus/CAE 2017 Documentation. Analysis User’s Manual, Simulia; 2017.

[21] V. Quaglini, E. Gandelli, P. Dubini, Numerical investigation of curved surfaced sliders under bidirectional orbits, Ingegneria Sismica - International Journal of Earthquake Engineering 2019, Vol. 2. 